Etnográfica

Revista do Centro em Rede de Investigação em

Antropologia

vol. 14 (3) | 2010

Vol. 14 (3)

\title{
Ismael Pordeus Jr., Portugal em transe: \\ Transnacionalização das religiões afro-brasileiras, conversão e performances
}

\section{Clara Saraiva}

\section{(2) OpenEdition}

Journals

\section{Edição electrónica}

URL: https://journals.openedition.org/etnografica/223

DOI: $10.4000 /$ etnografica.223

ISSN: 2182-2891

\section{Editora}

Centro em Rede de Investigação em Antropologia

\section{Edição impressa}

Data de publição: 1 outubro 2010

Paginação: 617-630

ISSN: 0873-6561

\section{Refêrencia eletrónica}

Clara Saraiva, «Ismael Pordeus Jr., Portugal em transe: Transnacionalização das religiões afro-brasileiras, conversão e performances», Etnográfica [Online], vol. 14 (3)| 2010, posto online no dia 04 outubro 2011, consultado o 12 fevereiro 2022. URL: http://journals.openedition.org/etnografica/223 ; DOI: https:// doi.org/10.4000/etnografica.223

Este documento foi criado de forma automática no dia 12 fevereiro 2022.

\section{(c) (1) \&}

Etnográfica is licensed under a Creative Commons Attribution-NonCommercial 4.0 International License. 


\title{
Ismael Pordeus Jr., Portugal em transe: Transnacionalização das religiões afro-brasileiras, conversão e performances
}

\author{
Clara Saraiva
}

\section{REFERÊNCIA}

Ismael Pordeus Jr., Portugal em transe: Transnacionalização das religiões afrobrasileiras, conversão e performances. Lisboa, Imprensa de Ciências Sociais, 168 páginas.

1 Este livro de Ismael Pordeus Jr. surge no seguimento do seu vasto trabalho sobre religiões afro-brasileiras (e em especial a umbanda) no Ceará e em Portugal. Organizado como um conjunto de narrativas compostas a partir da pesquisa encetada em 1995, baseia-se em várias épocas de trabalho em Portugal ao longo de doze anos, entre as quais se destacam estadias de terreno mais prolongadas em 1998 e de novo em 2005 e 2007.

2 Partindo da constatação da recomposição do campo religioso português após o 25 de Abril de 1974, com a subsequente abertura às mais variadas formas de religiosidade, o autor analisa a expansão das religiões afro-brasileiras no país e a forma como, passado um quarto de século após a revolução dos cravos, elas estão a constituir-se como componentes cada vez mais importantes desse mesmo campo religioso.

o primeiro capítulo fornece o quadro conceptual, identificando e analisando as perspectivas teóricas que lhe serviram de base, mas sintetizando também as temáticas que vão funcionar como fio condutor. $\mathrm{O}$ autor enumera assim as questões que serão debatidas ao longo do texto, que se revela multidimensional, ao entrecruzar as perspectivas teóricas com a descrição etnográfica e o diálogo com os informantes. 
4 Surgem assim tópicos como o da organização inicial da umbanda no Brasil, sobretudo no Rio de Janeiro, e os momentos primordiais da sua expansão para os países do Rio da Prata, seguida da sua travessia do Atlântico e instalação em Portugal e na Europa, salientando-se o quanto o papel das mulheres migrantes foi importante nesse processo. Aos aspectos ligados à relevância da possessão enquanto prática social - segundo as perspectivas teóricas de Berger, Bastide, Dianteil e Swearingen -, segue-se a explicitação de que as performances rituais irão ser analisadas à luz de Kristeva (por meio da noção de inter-ritualidades), Turner (utilizando sobretudo a concepção de liminaridade), Duvignaud (a perspectiva do ritual olhado enquanto jogo e teatro), Cazeneuve, Dawsey (no respeitante à leitura da performance como manuscrito), e ainda Leiris (de novo relativamente à possessão e aos seus aspectos teatrais, e à possessão olhada como o "momento da expressão", p.14). O autor completa estas incursões teóricas explicitando o quanto "o transe e a possessão codificam formas não verbais da performance e promovem abertamente a sua eficácia" (p. 15).

5 A partir desta noção de performance, Ismael Pordeus Jr. explicita como valoriza, neste seu trabalho, a oralidade performativa, isto é, as entrevistas e os diálogos encetados com os seus informantes. Seguindo uma orientação teórica e de escrita já utilizada em outras obras suas sobre as mesmas temáticas (Uma Casa Luso-Afro-Brasileira com Certeza, 2000; Magia e Trabalho: A Representação do Trabalho na Macumba, 2000; Umbanda: Ceará em Transe, 2002), o autor explica que delega na escrita "a oralidade performativa dos diálogos estabelecidos no campo, tal como a própria performance ritual", e que a escrita é "uma narração cuja urdidura inclui várias vozes: a do autor, mas, principalmente, a voz de todos aqueles que dizem e fazem as religiões afro-brasileiras em Portugal..." (p.15). Passando em revista as perspectivas de Bakhtine sobre as relações dialógicas e a função da linguagem, afirma optar por apresentar as narrativas transculturais luso-afro-brasileiras a partir da óptica bakhtiniana, apresentando a "língua do observado e do observador como uma construção dialógica muito especial, em que o discurso que representa estabelece uma relação de desmascaramento em relação ao discurso representado" (p. 16). Assim sendo, é através dos relatos e histórias de vida dos informantes que o autor estabelece essa "etnografia dialógica" do universo da expansão das religiões afro-brasileiras em Portugal, advogando a primazia da transcrição textual e da tradução, e a função dialógica desempenhada pelo intérprete e pelos informantes privilegiados (p. 39).

6 O restante do capítulo introdutório trata do cenário da composição e divulgação da umbanda no Brasil, revendo escritos clássicos (de Nina Rodrigues a Artur Ramos, Gilberto Freyre, Roger Bastide e Pierre Verger) e outros da história mais recente da literatura académica sobre essas religiões no seu país de origem (Renato Ortiz, Diana Brown, Liana Trindade, Vagner Gonçalves da Silva, Reginaldo Prandi, Giobelina Brumana e Martinez, Erwan Dianteil), e abordando aspectos ligados à representação de um elemento fulcral nesses contextos, a figura de Exú, como elemento mediador indispensável entre os homens e os orixás. A partir da concepção de Exú como "herói civilizador" (p. 19), Pordeus Jr. continua, sempre no contexto brasileiro, a explicar a expansão da umbanda e o seu sucesso no mercado religioso.

7 É a partir dessa constatação que o autor passa para a análise da transnacionalidade religiosa como a "adopção de formas culturais em mouvance" (p. 23) e para a abordagem do caso português, através da noção de festa aliada ao transe, pensados ambos como fenómenos de ruptura com o quotidiano. Possibilitados pela abertura religiosa 
pós-1974, o transe e a possessão aparecem assim, segundo o autor, como parte integrante das novas religiões em Portugal, e como elementos importantes na constatação da amplitude actual da oferta de serviços mágico-religiosos, facilmente visível na imprensa portuguesa, a que alude. Pelo seu carácter individualista de oferecimento de serviços, o autor põe estes casos, que denomina, mais uma vez na esteira de Turner, como anticommunitas, em contraste com a criação de comunidades religiosas integradas, ilustradas com os casos dos terreiros existentes em Portugal.

Os capítulos seguintes norteiam-se por uma conjugação feliz das perspectivas diacrónica e sincrónica que se manterá ao longo de toda a obra, e em que se entrecruzam, não só os vários testemunhos que o antropólogo foi recolhendo ao longo do seu percurso de pesquisa, mas também as histórias de vida e percursos individuais de cada informante.

9 Na perspectiva diacrónica, num primeiro momento, Pordeus Jr. reporta-se à instalação dos primeiros terreiros de umbanda em Portugal, quadro em que salienta a criação do terreiro Ogum Megê, de Mãe Virgínia de Albuquerque (sublinhando os dois factores importantes na constituição dos primeiros terreiros: as mulheres e o ciclo migratório), partindo depois para uma apresentação de outros ritualistas religiosos, explicitando como a partir desses primeiros casos se deu a multiplicação e a adesão dos portugueses a tais práticas.

10 Na aproximação sincrónica, é fornecido o panorama dos diversos terreiros existentes à data da escrita do texto (2008) no país. Com base no diálogo estabelecido com praticantes e ritualistas religiosos, tal como foi afirmado no capítulo inicial, são as histórias de vida de cada um deles que ilustram as diversas facetas das temáticas exploradas na obra (p. 32). Reforçando o quanto é importante, na escrita de Ismael Podeus Jr., o cruzamento da teoria com a exposição, os excertos de entrevistas e as histórias de vida "em directo", são várias as ocasiões em que o leitor é introduzido no universo dos terreiros e das práticas religiosas pelo discurso directo dos próprios personagens.

11 É assim que vamos percorrendo esse universo rico de ritualistas e de experiências vividas, com as histórias de vida das mulheres pioneiras que, oriundas do seu percurso migratório no Brasil ou noutros espaços, começaram a dedicar-se a tratar as "situações de aflição" dos portugueses (para além da de Virgínia de Albuquerque, aparecem as histórias de Fernanda e Georgete, Mariazinha, Ema Casimira, Maria Armanda e Teresinha de Goa). Seguem-se dois capítulos que dão conta das realidades dos actuais terreiros dos arredores da capital, desde o exemplo de casas que foram inicialmente filiais de casas-mãe, situadas no Brasil (como é o caso do templo Guaracy de São Paulo), até terreiros mais autónomos, fruto dos percursos individuais dos seus líderes religiosos, como o Terreiro de Pai Oxalá e Mãe Iemanjá, em Cortesia, ou a Casa de Caridade Maria de Nazaré, em Mafra, encimada pela figura da Mãe Virgínia.

12 A diversidade e riqueza das performances rituais, praticadas maioritariamente por portugueses, mas em que também surgem ritualistas religiosos brasileiros, é constatável pelas detalhadas descrições sobre a Jurema em Portugal, e ainda (no capítulo seguinte) pelas análises relativas a terreiros do Norte do país, nomeadamente a do Templo de Umbanda Pai Oxalá e Mãe Iansã (Tupomi), na Maia, ou do Templo de Umbanda Pai Oxalá (Atupo), em Braga.

Os dois capítulos finais tratam do que o autor denomina "inter-ritualidades", e aí são focados aspectos em que se entrecruzam performances católicas (como o lava-pés de 
Quinta-Feira Santa num terreiro de umbanda em Lisboa), ou jogos de adivinhação africanos e afro-brasileiros (como o jogo de búzios e de tarot), com devoções a santos populares em capelas do litoral nortenho e performances que ilustram facetas do complexo universo da religiosidade popular portuguesa.

O último caso relatado, acerca do surgimento, no terreiro de Braga, de uma entidade portuguesa no panteão umbandista, o marinheiro Agostinho, é mais um exemplo que demonstra o quanto uma variante lusitana das religiões afro-brasileiras parece estar em plena criação. Isto é ademais afirmado na conclusão, em que o autor reforça a noção da importância do triângulo África--Portugal-Brasil, e como o Brasil é olhado como fonte de legitimação (tanto pelos praticantes como pelos líderes religiosos) no processo de transnacionalização destas religiões para Portugal.

15 Se algumas das questões debatidas haviam sido anteriormente focadas em Uma Casa Luso-Afro-Brasileira com Certeza, elas são aqui retomadas e aprofundadas. A profusão de descrições pormenorizadas e a opção do autor de fornecer os discursos directos dos informantes, que nos são apresentados sem passarem pela peneira crítica do antropólogo, abrem-nos um mundo de experiências vividas e de realidades etnograficamente muito ricas. Como tal, esta é uma obra de leitura imprescindível, não só para qualquer analista social que se dedique ao estudo das religiões afro-brasileiras, mas, de um modo mais geral, para qualquer interessado na antropologia da religião e no panorama actual da reconfiguração do campo religioso português. 